\title{
Computer Applications in Psychiatry: Role in Patient Care, Education, Research and Communication
}

\author{
WAGUIH WILLIAM IsHAK, M.D. AND TAL BURT, M.D.
}

\begin{abstract}
In recent years, computer use has pervaded almost every aspect of the practice of medicine. Although computers have been in use in psychiatry since the early 1950s, it was the last decade that has witnessed the greatest growth. While computers cannot replace the careful attention and compassion of human contact, they can perform standardized operations much faster and more accurately. The current interest in computer use is associated with two phenomena: one is the availability of home, office, and portable computers; and the other is the exponential growth in the information that has to be processed in order to deliver optimal care. Computers have advanced patient care through improvements in documentation, evaluation, and treatment modalities (e.g., virtual reality). They have advanced education by providing convenient access to academic resources, adding decision support modules to electronic records, and by introducing educational software. Research was promoted through the use of sophisticated statistical tools, the convenience of access to clinical databases, and through the introduction of new evaluation and treatment modalities. Communication on intranets and on the Internet has significantly improved all aspects of psychiatric practice. Specific topics that require further development and clarification include: electronic records, confidentiality in electronic networks, the role of telepsychiatry and virtual reality in psychiatric treatment and rehabilitation.
\end{abstract}

\section{COMPUTERIZED RECORDS}

$\mathrm{C}$ OMPUTERIZED PATIENT RECORDS uses computer technology, including artificial intelligence, to transform raw data into usable information on a time vector. Easy input and output, easy data search, and simultaneous use, have made the relational database popular. With increasing amounts of clinical information gathered on each patient, such databases will become indispensable. They enable the treatment team to view pertinent information graphically and concisely. For example, the course of bipolar disorder can be represented graphically, showing intensity and duration of symptoms during episodes. Instant feedback relevant to the information entered into

NYU School of Medicine, New York, NY 10016. the system can be given, as in the case of the presence of potential drug interaction when the clinician adds a new medication. An updated patient profile is provided that can be simultaneously used by all members of the interdisciplinary team. To some, the field-oriented database violates the narrative and individual nature of the psychiatric report. A hybrid of both predetermined fields, and free text fields was an obvious first compromise to the problem. Are there other solutions?

\section{COMPUTERS AS A SOURCE OF INFORMATION FOR CLINICIANS}

Clinical management of psychiatric patients requires processing of extensive amounts of information that exceeds the ability of any in- 
dividual clinician, such as having access to pertinent literature updates and textbook information on practice guidelines and drug interactions. Access to reference material can significantly reduce the reaction time to any clinical dilemma through:

- The ability to use personal computers to access this information from any location (e.g., home or office)

- The ability to use powerful searching capabilities in locating desirable information and increasing the yield of the search.

Computerized reference materials are userfriendly, cost-effective and time-saving. Several hundred titles are available for use as software or online, e.g., Physician's Desk Reference, DSM-IV, and Merck Manual. Access to abstracts of all published articles are provided by professional journals, Medline, and PsychInfo. Full-text articles are also available.

\section{COMPUTER USE AS A SOURCE OF INFORMATION FOR PATIENTS AND THEIR FAMILIES}

Computerized psychiatric information resources promoting psychoeducation are available to patients and their families. Reduction of relapse rate in certain psychiatric disorders has been proven to be reduced by psychoeducation. Vast amounts of information on psychiatric disorders and treatment are currently available on the Internet. Isolated patients can also gain access to support and advocacy groups. For example, support groups for sexual abuse survivors, as well as the National Alliance of Mentally Ill (NAMI) can be found on the Internet.

\section{COMPUTER USE IN PSYCHIATRIC EVALUATION}

Computer technology is being used in all phases of psychiatric evaluation (i.e., screening assessment and diagnosis as detailed below). Some aspects of psychiatric evaluation can be automated. One advantage of using computers for psychiatric evaluation is standardization by eliminating biases of personal interviewing styles, thus achieving a unified approach to diagnosis. This will not undermine the value of the psychodynamic assessment and certainly cannot replace it.

\section{Screening}

Screening tests for self-administration can be found on the Internet (e.g., NYU Psychiatry website). They allow users, in the privacy of their own locale, to self-evaluate symptoms of various disorders, including depression, anxiety, sexual disorders and attention deficit disorder. ${ }^{1}$ Bagley et al. reported that a computerized questionnaire elicited significantly more recall of prior sexual abuse in a population of young adult males. ${ }^{2}$ Kennedy et al. reported self-administration of a battery of mental acuity tests used in screening for fitness-for-duty or for persons who may be exposed to environmental stress, toxic agents, or disease. ${ }^{3}$

\section{Assessemnt}

Assessment tools (e.g., the Beck Anxiety Inventory, MMPI), have been used in computerized forms. Baer et al. at Massachusetts General Hospital used a computer-assisted telephone system to administer rating scales for obsessive-compulsive disorder (OCD) providing a tool for reliable, low-cost, and instantaneous data acquisition. ${ }^{4}$ Moore et al. showed that patients were almost unanimous in finding the computer acceptable and easy to use. ${ }^{5}$ Computer programs have been used to elicit personal histories from in-patients. ${ }^{6}$ Carr et al. compared patients' answers with the information recorded by the psychiatric team. In the computer-elicited case histories, 93\% of items were correct. They reported that most computer histories revealed information that was unknown to the clinicians and of proven importance to patient treatment. By sending their personal histories using electronic mail, patients can receive professional psychiatric evaluations of their condition and get appropriate referral for further management. This can extend the outreach of psychiatric services to individuals who are intimidated by conventional modes of referrals, geographically isolated, or experiencing psychiatric emergencies. 


\section{Diagnosis}

Computer-assisted diagnosis systems have been in use for many years. Diagnostic algorithms are decision-making trees that take the clinician successively through series of yes/no questions to a list of putative diagnoses. The major advantage of algorithms is that they direct the clinician to systematically explore all aspects of the patient's presentation. Murphy et al. demonstrated a sensitivity of $92 \%$, and a specificity of $98 \%$ in one system. ${ }^{7}$ The use of diagnostic instruments (e.g., SCID) has made psychiatric diagnosis more amenable to computerization.

\section{COMPUTER USE IN TREATMENT AND REHABILITATION}

\section{Treatment}

A virtual reality (VR) technique has been used as a behavioral therapy to treat acrophobia. Graded exposure to heights was delivered using VR, and has proven to be successful in a controlled study of Rothbaum et al. ${ }^{8}$ Virtual reality has been also used in the treatment of other phobias, autism, dissociative identity disorder, and schizophrenia. A case study by Baer et al. on using a portable computer program reported improvement of symptoms in OCD. Computer programs have been used in psychotherapy as a virtual therapist (e.g., the Eliza program) to provide an interactive medium for the patient. However, no data are available on the efficacy of this type of procedure. In addition, some concerns have been raised about the possible dehumanization of the therapeutic process using these techniques.

\section{Rehabilitation}

Computers have been used in the rehabilitation process of chronic psychiatric disorders and intellectual deterioration. It is possible that communication hampered by lack of interpersonal skills can be facilitated by interaction with computers. Brieff et al. reported that patients at a rehabilitation program acquired skills at their own pace, showed considerable enthusiasm, and were able to overcome cognitive and motivational limitations. They were taught computer applications in a vocational rehabilitation program and were able to improve their spelling, grammar, math, and vocabulary skills. ${ }^{9}$ Hermanutz et al. demonstrated the reduction of distraction in patients with schizophrenia using a computer-assisted attention training program. ${ }^{10}$ Hoffman et al. using a PC touch-screen for cognitive rehabilitation of patients with Alzheimer's disease observed emotional activation and improvement in social competence and orientation. These reports, although still anecdotal, point to the potential of computer-assisted training to achieve improvement in what was previously believed to be refractory conditions.

\section{COMPUTER USE IN TREATMENT MONITORING AND OUTCOME MEASUREMENT}

Assessment of outcome can be standardized and obtained readily in automated systems. The severity of symptoms, level of functioning, response to treatment, and cost can be followed over time. Overall et al. developed a monitoring system that generated a weekly status report for each patient allowing the clinician to identify potential problems regarding drug treatment and discharge decisions. ${ }^{11}$ Hammond et al. developed an automated reminder system that improves physicians' monitoring of patients receiving neuroleptics by promoting early recognition and treatment of tardive dyskinesia. ${ }^{12}$ The above applications have legal implications and are particularly useful in managed care environment.

\section{COMPUTER USE IN INFORMATION EXCHANGE AND CONTINUITY OF CARE}

\section{Telepsychiatry}

Telepsychiatry is the use of online videoconferencing for delivery of psychiatric services, and was found to be invaluable. Telepsychiatry is the use of telemedicine for psychiatric purposes. Telemedicine involves healthcare applications of telecommunications technologies, including videoconferencing, television, 
telephony, FAX, and the Internet. This can include providing medical care to patients at a distance (e.g., the use of live interactive video to examine patients in remote locations or cable TV to provide in-home service for homebound patients). It also includes electronic transmission of patient records and X-rays; expert consultations to distant sites; and distance learning for health professionals and patient education. Telemedicine extends healthcare applications to remote rural locations and to medically underserved areas. Telepsychiatry thus applies telecommunications technologies to consultation, treatment, education, administrative meetings (e.g., commitment hearings), and research at distant sites. Telepsychiatry has a major role in information retrieval and exchange in psychiatric emergencies.

\section{LIMITATIONS}

Confidentiality of electronically stored patient data is one of the limitations of computer use in psychiatric settings. ${ }^{13}$ These concerns have been addressed by implementing sophisticated data protection systems (e.g., use of passwords, encryptor and firewalls). Some clinicians are intimidated by computer technology, resisting its integration into their practice. Computer anxiety groups have been devised to address this problem, and computer education are currently being added to psychiatry training curricula. Other clinicians are concerned that the essential component of human contact will be insufficient or lost. It is important to emphasize that computers function as an extension of the clinician's abilities, not a replacement. $^{14}$

\section{CONCLUSION}

The growing number of computerized clinical applications is a promising contribution to the field of psychiatry. Notwithstanding the limitations and empirical nature of some reports, there is a growing evidence of the invaluable role of computer technology in psychiatric care.

\section{REFERENCES}

1. Lim, R.F. (1996). The Internet: applications for mental health clinicians in clinical settings, training, and research. Psychiatr Serv, 47, 597-599.

2. Bagley, C., Genuis, M. (1991). Psychology of computer use: XX. Sexual abuse recalled: evaluation of a computerized questionnaire in a population of young adult males. Percept Mot Skills, 72, 287-288.

3. Kennedy, R.S., Baltzley, D.R., Wilkes, R.L., Kuntz, L.A. (1989). Psychology of computer use: IX: A menu of self-administered microcomputer-based neurotoxicology tests. Percept Mot Skills, 68, 1255-1272.

4. Baer, L., Brown-Beasley, M.W., Sorce, J., Henriques, A.I. (1993). Computer-assisted telephone administration of a structured interview for obsessive-compulsive disorder. Am J Psychiatry, 150, 1737-1738.

5. Moore, N.C., Summer, K.R., Bloor, R.N. (1984). Do patients like psychometric testing by computer? J Clin Psychol, 40, 875-877.

6. Carr, A.C., Ghosh, A., Ancill, R.J. (1995). Can a computer take a psychiatric history? Psychol Med, 13, 151-158.

7. Murphy, J.M., Neff, R.K., Sobol, A.M., Rice, J.X., Jr, Olivier, D.C. (1985). Computer diagnosis of depression and anxiety: the Stirling County Study. Psychol Med, 15, 99-112.

8. Rothbaum, B.O., Hogdes, L., Kooper, R. Opdyke, D., Wiliford, J.S., North, M. (1995). Effectiveness of computer-generated (virtual reality) graded exposure in the treatment of acrophobia. Am J Psychiatry, 152, 626-628.

9. Brieff, R. (1994). Personal computers in psychiatric rehabilitation: a new approach to skills training. Hosp Community Psychiatry, 45, 257-260.

10. Hermanutz, M., Gestrich, J. (1991). Computer-asstisted training in schizophrenics. A comparative study. Eur Arch Psychiatry Clin Neurosci, 240, 282-287.

11. Overall, J.E., Faillace, L.A., Rhoades, H.M., Johnson, S.R., Volkow, N., Stone, M.A., Cecil, S. (1987). Computer-based monitoring of clinical care in a public psychiatric hospital unit. Hosp Community Psychiatry, 38, 381-387.

12. Hammond, K.W., Snowden, M., Risse, S.C., Adkins, T.G., Obrien, J.J. (1995). An effective computer-based tardive dyskinesia monitoring system. Am J Med Qual, 10, 133-137.

13. Delmar, D. (1996). Can statewide database protect confidentiality? Clinical Psychiatry News, May 1996.

14. Modai, I., Rabinowitz, J. (1993). Why and how to establish a computerized system for psychiatric case records. Hosp Community Psychiatry, 44, 1091-1095.

Address reprint requests to: Waguih William IsHak, M.D. NYU Medical Center

550 First Avenue, NB20N11

New York, NY 10016

E-mail: wwi1@is2.nyu.edu 
This article has been cited by:

1. Ivan L. Beale . 2002. An Evaluation Model for Psychoeducational Interventions Using Interactive MultimediaAn Evaluation Model for Psychoeducational Interventions Using Interactive Multimedia. CyberPsychology \& Behavior 5:6, 565-580. [Abstract] [PDF] [PDF Plus] 